\title{
Modelo de avaliação do nível de sustentabilidade urbana: proposta para as cidades brasileiras
}

\author{
Assessment model of urban sustainability level: proposal to brazilian cities
}

Maria de Fátima Martins, Gesinaldo Ataíde Cândido

Universidade Federal de Campina Grande (UFCG), Campina Grande, PB, Brasil

\section{Resumo}

Os indicadores de sustentabilidade permitem captar características do ambiente urbano e revelar a (in) sustentabilidade urbana, gerando informações que dão suporte às políticas públicas e ao processo de desenvolvimento. A partir dessa constatação, o objetivo do artigo é propor um modelo para análise da sustentabilidade urbana, construído a partir das matrizes de Acselrad (2009). Tal proposta é dividida em: uma abordagem conceitual, marco ordenador para avaliação da sustentabilidade do espaço urbano, no sentido de unificar o entendimento sobre a sustentabilidade pelos diversos públicos interessados; e uma abordagem operacional, que define as matrizes, as dimensões e os temas para análise da sustentabilidade, com seus respectivos critérios de análises, indicadores e parâmetros de operacionalização, que permitem o monitoramento da sustentabilidade das cidades, servindo como instrumento para orientação das políticas públicas urbanas. Em termos metodológicos, trata-se de um ensaio teórico baseado na literatura sobre sustentabilidade urbana, especialmente acerca das matrizes discursivas. A importância do trabalho refere-se ao fato de o modelo permitir a análise da sustentabilidade urbana, dadas as especificidades da problemática das cidades brasileiras. Em termos de contribuição, é importante por gerar subsídios para análises mais consistentes desses problemas e, por meio de indicadores urbanos e de critérios de análises, possibilitar uma orientação para o processo de desenvolvimento urbano e de monitoramento da sustentabilidade das cidades, oferecendo suporte às políticas públicas.

Palavras-chave: Sustentabilidade. Indicadores urbanos. Políticas públicas.

\section{Abstract}

Sustainability indicators allow to capture urban environment features and reveal the urban (in)sustainability, generating information that support urban public policies and the development process. Based on this evidence, the paper aims to propose a model for urban sustainability analysis, built from matrices of Ascelrad (2009). This proposal is divided into a conceptual approach, originator mark for assessing the urban space sustainability in order to consolidate the its by various stakeholders and an operational approach defining matrices, the dimensions and the themes for sustainability analysis, with their analysis criteria, indicators and operational

MFM é doutora em Recursos Naturais, e-mail: fatimamartins2005@gmail.com GAC é doutor em Engenharia de Produção, e-mail: gacandido@uol.com.br 
parameters, which allow to monitor the cities sustainability, serving as a tool for guidance of urban public policies. Methodologically, this is a theoretical essay based on the literature on urban sustainability, especially urban sustainability discursive matrices. This model allows the analysis of urban sustainability given the specificities of the Brazilian urban issues; and contributes to generate subsidies for more consistent analyzes of urban problems, which through urban indicators and criteria analysis, allow a guidance to the urban development process and cities sustainability monitoring, offering support to public policies.

Keywords: Sustainability. Urban indicators. Public policy.

\section{Introdução}

É consenso na literatura que o meio urbano, entendido como o espaço que agrega o meio natural e o ambiente construído, apresenta uma dinâmica de organização relacionada à evolução da sociedade e às relações de poder estabelecidas ao longo de sua história.

Considerando que o urbano é a forma de ocupação do espaço por uma população aglomerada, resultante de uma forte concentração e da alta densidade (Castells, 2000), o meio urbano é um grande propulsor de impactos, pois reúne diversas atividades produtivas e de comercialização, sistema de transportes com tráfego de veículos, maior concentração de população, maior consumo e produção de resíduos etc., que exercem pressão sobre os recursos naturais. Mendonça (2001) ratifica essa ideia ao enfatizar que fatores como industrialização, produção, circulação e consumo de mercadorias, bem como a concentração populacional nas cidades, promoveram a explosão urbana e introduziram, paulatinamente, a degradação dos ambientes urbanos.

Diante disso, percebe-se que a compreensão do fenômeno urbano envolve percepções e interpretações que, somadas a um conjunto de interesses distintos presentes no espaço urbanizado, geram toda a complexidade que envolve o contexto urbano e estabelece as bases para o processo de desenvolvimento sustentável das cidades. Acselrad (2009), ao investigar os diversos discursos da sustentabilidade, destaca a existência de várias articulações lógicas entre a reprodução das estruturas urbanas e a sua base especificamente material e, assim, encontra representações distintas da cidade capazes de legitimar e dar durabilidade à integridade do urbano. São elas: 1) A representação técnico-material da cidade, mediante associação entre a transição da sustentabilidade e a reprodução adaptativa das estruturas urbanas para ajustamento das bases técnicas das cidades; 2) A representação da cidade como espaço da qualidade de vida, expressa por meio de componentes não mercantis das áreas urbanas, especialmente as implicações sanitárias das práticas urbanas; 3 ) A representação da cidade como espaço de legitimação das políticas urbanas, por meio das quais a materialidade das cidades é politicamente construída.

Em busca de responder adequadamente ao fenômeno da sustentabilidade, Acselrad (1999, p. 81) esclarece que prevalecem as expressões interrogativas, nas quais a sustentabilidade é vista como algo em evolução, enfatizando que "[...] é sustentável hoje aquele conjunto de práticas portadoras da sustentabilidade no futuro". Nessa perspectiva, Braga (2006) destaca que a sustentabilidade urbana não apresenta definição acabada, sendo fundamental compreender seu papel no estabelecimento de uma "verdade" para torná-la mais operacional e mensurável, mediante a criação de indicadores que permitem captar as características do ambiente urbano investigado e revelar a (in) sustentabilidade urbana. Assim, os aspectos conceituais da sustentabilidade e a problemática urbana representam o ponto de partida para a identificação e para a criação de indicadores de sustentabilidade urbana, cujos sistemas constituem instrumentos que permitem avaliar os processos de desenvolvimento e sustentabilidade das cidades. Para atender a propósitos distintos, diversos sistemas de sustentabilidade urbana já foram construídos, com destaque para o Sistema de Índices de Sustentabilidade Urbana (SISU), o Índice de Qualidade de Vida Urbana dos Municípios Brasileiros (IQVU-BR), o Sistema Nacional de Informações das Cidades (SNIC), o Sistema Integrado de Gestão do Ambiente Urbano (SIGAU), entre outros.

No entanto, os estudos sobre o desenvolvimento do espaço urbano precisam ser viabilizados por mecanismos capazes de prever os impactos e dar novos cursos de ação que ofereçam opções sustentáveis, por 
meio de evidências que revelem, pelo monitoramento dos indicadores e das políticas públicas, tendências ou perspectivas futuras (Martins \& Cândido, 2013), mediante a definição de critérios de análise e de parâmetros de comparação.

Nesse sentido, o presente artigo propõe um modelo para análise da sustentabilidade urbana, a partir das matrizes de Acselrad (2009), e constitui um ensaio teórico baseado em uma revisão de literatura sobre a temática sustentabilidade urbana, indicadores e sistemas de indicadores urbanos, especialmente acerca das matrizes discursivas. Ressalta-se que o modelo parte das concepções teóricas a partir da leitura das matrizes da sustentabilidade urbana e estabelece uma relação com a realidade prática, por meio dos indicadores urbanos, para gerar informações que permitem uma orientação para as políticas públicas e para o processo de desenvolvimento urbano das cidades. Assim, sua relevância está em disponibilizar um modelo de monitoramento da sustentabilidade abrangente à problemática urbana brasileira, sendo flexível para atender às condições urbanas locais e dar suporte ao processo de desenvolvimento das cidades.

0 presente artigo apresenta, além desta parte introdutória, questões teóricas relativas ao espaço urbano e à sustentabilidade urbana, seguido do modelo proposto de sustentabilidade das cidades, no qual foram inseridos um conjunto de indicadores que adequam a realidade das cidades brasileiras às matrizes da sustentabilidade urbana, e, por fim, as considerações finais do estudo e as referências utilizadas.

\section{O espaço urbano e as questões da sustentabilidade}

Levando-se em consideração que a cidade é uma construção humana antiga, cuja concepção genérica pode ser expressa pela aglomeração de pessoas, de equipamentos, de edificações e pelo dinamismo das atividades de um determinado local, para compreendê-la torna-se necessário partir das mais completas estruturas e funções urbanas atuais e conhecidas para os seus componentes originários, por mais remotos que se apresentem no tempo, no espaço e na cultura (Mumford, 2008). Assim, para entender a ordem urbana que se apresenta hoje, é preciso mergulhar mais profundamente na história da cidade, entendendo suas peculiaridades, vulnerabilidades e potencialidades, para estimular a expansão urbana de forma ordenada. Na visão de Castells (2000), as contradições urbanas devem ser tratadas mediante uma transformação das fontes estruturais dos processos de urbanização.

As cidades, em geral, quando surgem e crescem de forma desordenada ou com formas de planejamento ineficiente, não conseguem atender à demanda da população urbana em relação à infraestrutura e aos serviços urbanos, tornando-se o berço de diversos problemas sociais, ambientais, econômicos, políticos etc. De acordo com Moreno (2002), nas primeiras décadas do século $\mathrm{XX}$, apenas $10 \%$ da população vivia nas cidades. A partir de então, esse crescimento deu-se de forma exponencial, caracterizado pela expansão das estradas de ferro, pelo aparecimento do automóvel, pelo transporte urbano, pelas novas redes de serviços urbanos e pelos arranha-céus, elementos esses que foram os maiores responsáveis pela dinâmica da expansão urbana.

É possível observar que, desde as pequenas cidades da Antiguidade até as megalópoles, nas quais há significativa concentração da população urbana, houve grandes transformações na sociedade e no estilo de vida. Na medida em que se percebe o crescimento exponencial da pobreza, há, no entanto, a crescente incapacidade dos governos em planejar, financiar e administrar suas cidades, aumentando os males sociais e as patologias urbanas, tais como violência, epidemias, entre outras. Dessa forma, um dos maiores obstáculos enfrentados pela sociedade diz respeito à crescente dificuldade em adequar as necessidades ao inevitável crescimento urbano (Canepa, 2007).

Uma justificativa para existência das cidades consiste na facilidade do acesso a um conjunto de produtos, serviços e infraestrutura necessários à vida e à satisfação de uma população, constituindo-se em espaços que reúnem uma diversidade de pessoas e suas ilimitadas necessidades de sobrevivência, as quais exercem pressão no crescimento urbano. Essas necessidades estão relacionadas, principalmente, às atividades de produção e de consumo da sociedade, cujas consequências são externalidades positivas ou negativas que favorecerão o processo de desenvolvimento da cidade. Silva \& Travassos (2008) compartilham dessa ideia e enfatizam que as mudanças nos padrões produtivos e nas dinâmicas populacionais modificam a natureza desses impactos e as condições socioambientais das aglomerações urbanas. 
Em virtude de um modelo obsoleto e irracional da ocupação do espaço, quase todas as sociedades enfrentam a desanimadora perspectiva de uma infindável crise urbana, especialmente nas grandes aglomerações urbanas, nas quais a acumulação das riquezas e a má distribuição dos benefícios sociais têm aumentado os conflitos e as contradições, além de provocarem a rápida e intensa industrialização. Assim, a concentração da população nas áreas urbanas tem transformado as cidades em lugar oposto à sua proposta, que é de ser um lugar para se viver bem (Rattner, 2009). Diante disso, vale ressaltar a percepção de Rogers (2008), quando coloca que as cidades cresceram e transformaram-se em estrutura tão complexas e difíceis de administrar que raramente são lembradas como um espaço para satisfação das necessidades humanas e sociais da população.

Assim, a cidade pode ser descrita como um espaço em que se colhem os frutos das rápidas transformações das últimas décadas. Devido a fenômenos como a exaustão da economia industrial, a globalização, a diversidade cultural, a transformação da composição familiar e os avanços tecnológicos, tem-se a emergência por modos de vida que gerem novas formas de aglomeração urbana, o que configura um significativo desafio (Moreno, 2002). Nesses termos, para reorganização do espaço urbano, exige-se cada vez mais o planejamento desses espaços para atender ao propósito de ser um lugar para viver bem, pois, de acordo com Rogers (2008, p. 7), "[...] a capacidade das cidades está sendo solicitada até o limite, sua expansão se dá em tal índice que os padrões tradicionais de acomodação do crescimento urbano tornaram-se obsoletos".

Entretanto, é necessário ressaltar que as cidades não nascem grandes; elas se formam e constroem sua identidade a partir de um conjunto de aspectos que se fundem para formar um ambiente de complexas relações, podendo ser gerenciadas para respeitar as limitações impostas pela natureza em termos de capacidade de resiliência, bem como limitações relacionadas aos aspectos sociais, econômicos, institucionais etc., formados para criar as condições para o funcionamento das cidades. Metzger (1994) afirma que as percepções da natureza da cidade em seus elementos biológicos, físicos e naturais, dos riscos naturais físico-químicos, biológicos, climáticos, tecnológicos e de segurança em relação à saúde da população, e da gestão democrática dos serviços urbanos, em função da existência de políticas públicas, constituem formas de compreensão da problemática desses espaços.

Bremer (2004) postula que a reordenação do espaço urbano, com base em princípios básicos sustentados no direito à cidadania, na administração democrática das cidades e na função social destas e da propriedade, assim como a adoção de mecanismos que incluam, no mínimo, a manutenção dos atuais estoques de recursos para as gerações futuras, emerge como uma alternativa factível, mas que depende do empenho do Poder Público e da participação da sociedade civil.

Diante da diversidade de percepções em torno das questões urbanas e da sustentabilidade, Acselrad (2009) investiga os discursos sobre sustentabilidade urbana, destacando a existência de várias articulações lógicas, denominadas matrizes discursivas da sustentabilidade urbana: a primeira matriz consiste na representação técnico-material das cidades, a partir dos modelos de racionalidade ecoenergética e de metabolismo urbano. No primeiro modelo, a cidade é vista a partir de um vetor de consumo de espaço, energia e matérias-primas e de um vetor de produção de rejeitos, considerando-se a distribuição das populações e as suas atividades no espaço urbano. Essas pressões técnicas das práticas urbanas apontam para a necessidade da adoção de tecnologias poupadoras de espaço, matéria e energia, voltadas para a reciclagem de materiais, bem como para a constituição de uma base social de apoio a projetos de mudança técnica urbana. Assim, será sustentável a cidade que,

[...] para uma mesma oferta de serviços, minimiza o consumo de energia fóssil e de outros recursos materiais, explorando ao máximo os fluxos locais e satisfazendo o critério de conservação de estoques e de redução do volume de rejeitos (Acselrad, 1999, p. 82).

0 ajustamento técnico-material das bases da cidade pode ocorrer por meio do modelo de metabolismo urbano, ou seja, pelo ajustamento dos fluxos e dos estoques de matéria e de energia para reprodução ecossistêmica das cidades, mediante os movimentos interativos de circulação, troca e transformação de recursos, baseados na capacidade adaptativa (resiliência) dos ecossistemas urbanos em superarem as condições de vulnerabilidades diante dos choques externos. Nesse caso, a insustentabilidade seria expressa pela "[...] incapacidade de reprodução adaptativa das estruturas urbanas diante de rupturas nas condições 
materiais requeridas para tal reprodução" (Acselrad, 1999, p. 84). Assim, a cidade sustentável seria aquela que apresenta a capacidade adaptativa para ajustar seus fluxos materiais e de energias ante as pressões técnicas urbanas.

A segunda matriz discursiva consiste na cidade como espaço de "qualidade de vida", caracterizada por componentes não mercantis da existência cotidiana e cidadã da população urbana, especialmente em relação às questões sanitárias das práticas urbanas, envolvendo o modelo de pureza, cidadania e patrimônio. Nesse sentido, é possível pensar na qualidade de vida a partir do ponto de vista de Left (2000), que estabelece uma relação entre a qualidade de vida e a qualidade do ambiente, mediante a conservação do potencial produtivo dos ecossistemas e a valorização e a preservação dos recursos naturais, estando relacionada também às formas de identidade, cooperação, participação, solidariedade e realização, visando à promoção dos direitos e da cidadania para uma vida sadia e produtiva.

Assim, a cidade é avaliada a partir: do modelo de pureza, como forma de questionar as bases técnicas (tecnologias e atividade de produção e de consumo) do urbano, que, por sua artificialidade, poderiam impregnar a população com substâncias nocivas e tóxicas; do modelo de cidadania, visando à realização de pactos para dar sentido à duração das cidades; do modelo de patrimônio, referente aos aspectos materiais e imaterais (caráter, identidades, valores e heranças), construídos ao longo da história da cidade, que fazem durar a existência simbólica dos patrimônios natural e construído, expressos pelos aspectos históricos, culturais e ambientais que permitem fortalecer as raízes e as origens do seu povo, bem como conservar as identidades locais.

É nesse contexto que surge a terceira matriz discursiva de Acselrad (2009), na qual a cidade é vista como espaço de legitimação das políticas urbanas, por meio das quais a materialidade das cidades é politicamente construída e as modalidades de sua reprodução são consideradas dependentes das condições que legitimam seus pressupostos políticos. Essa matriz pode ser expressa pelo modelo de eficiência mediante a gestão dos recursos públicos e pela equidade evidenciada na disposição em democratizar o acesso aos serviços urbanos, demonstrando a capacidade das políticas urbanas na adaptação da oferta de serviços urbanos à quantidade e à qualidade das demandas da sociedade, para promover o equilíbrio entre a oferta e a demanda. Nesse caso, a insustentabilidade seria "[...] a incapacidade das políticas urbanas adaptarem a oferta de serviços urbanos à quantidade e qualidade das demandas sociais" (Acselrad, 1999, p. 85).

As matrizes discursivas da sustentabilidade urbana, portanto, abordam de forma conceitual a questão da sustentabilidade do espaço urbano, no intuito de dar um sentido durável à cidade que surge, cresce e se transforma com a evolução da sociedade, mediante as relações estabelecidas entre o homem e o meio ambiente, para construir um espaço urbano com melhores condições ao longo de sua existência e do processo de desenvolvimento. No entanto, os sistemas de indicadores constituem o caminho para mostrar a realidade urbana e apontar as diretrizes para a definição e a implementação de políticas públicas que resultem em áreas urbanas com condições mais adequadas para o desenvolvimento das cidades em bases mais sustentáveis.

Nesse sentido, o presente estudo direciona seus esforços para construir um modelo conceitual e operacional para análise da sustentabilidade de cidades, tomando como subsídio teórico as matrizes discursivas da sustentabilidade urbana de Acselrad (2009). 0 modelo proposto compõe-se de matrizes, dimensões e temas, com os respectivos critérios para análise da sustentabilidade, seguido da incorporação dos indicadores para compor um sistema de sustentabilidade que permite avaliar os processos de desenvolvimento, evidenciados pelo nível de sustentabilidade urbana.

\section{Modelo para análise da sustentabilidade urbana}

A análise da sustentabilidade urbana parte das três principais vertentes (matrizes), nas quais a sustentabilidade é discutida teoricamente. Assim, foi estabelecido o seguinte critério para analisá-la: uma cidade será mais sustentável, quanto melhor for sua a continuidade material dos fluxos e dos estoques de recursos, a qualidade de vida, a legitimação e a reprodução das políticas públicas urbanas. No caso específico do modelo proposto, cada indicador, dentro de cada uma das matrizes e temas, é avaliado positiva ou negativamente, ou seja: no primeiro caso (relação positiva), quanto maior o indicador, melhor sua contribuição para a sustentabilidade; ou quanto menor, pior sua contribuição; no segundo caso (relação negativa), quanto maior for o indicador, pior será 
sua contribuição para a sustentabilidade; ou quanto menor o indicador, melhor para a sustentabilidade.

Em relação à matriz 1, uma cidade em sua representação técnico-material, tem-se o seguinte critério de análise: uma cidade terá melhor continuidade material de estoques e de fluxos de recursos e rejeitos, quanto mais adequadas forem suas práticas em busca da racionalidade ecoenergética e de seu metabolismo urbano, que são as dimensões dessa matriz.
A dimensão 1, racionalidade ecoenergética, é avaliada a partir do seguinte critério: uma cidade apresentará racionalidade ecoenergética quando, para uma mesma oferta de serviços, conseguir minimizar o consumo de energia e de outros recursos materiais, explorando ao máximo os fluxos locais e conservando o estoque e a redução de rejeitos. Os temas desta dimensão encontram-se no Quadro 1, com a descrição, o critério de análise, os respectivos indicadores (I) e a definição do tipo de relação com a sustentabilidade (+ e -).

Quadro 1 - Temas, critérios e indicadores da dimensão racionalidade ecoenergética

(continua)

Dimensão 1 : racionalidade ecoenergética

\begin{tabular}{|c|c|c|}
\hline Tema 1 e critério & Indicadores & $\begin{array}{l}\text { Relação com a } \\
\text { sustentabilidade }\end{array}$ \\
\hline \multirow{9}{*}{$\begin{array}{l}\text { Tema 1: } \\
\text { Consumo de energia e de combustível para manter } \\
\text { o funcionamento da cidade. } \\
\text { Critério: } \\
\text { Uma cidade terá reduccão no consumo de energia } \\
\text { e gasolina quando utilizar adequadamente seus } \\
\text { recursos disponíveis. }\end{array}$} & I 1: FIC: Número de vezes que o cliente ficou sem energia ao ano. & Negativa (-) \\
\hline & I 2: DIC: Número de horas que o cliente ficou sem energia durante 0 ano. & Negativa $(-)$ \\
\hline & I 3: DMIC: Duração, em horas, da maior interrupção de energia no período. & Negativa (-) \\
\hline & I 4: Consumo médio de energia elétrica urbana (kWh/cons.). & Negativa (-) \\
\hline & I 5: Tarifa de energia (R\$/kWh) das residências. & Positiva (t) \\
\hline & I 6: Consumo per capita de diesel. & Negativa (-) \\
\hline & I 7: Consumo per capita de gasolina. & Negativa (-) \\
\hline & I 8: Consumo per capita de álcool. & Negativa (-) \\
\hline & I 9: Consumo per capita de GNV. & Positiva (+) \\
\hline \multirow{6}{*}{$\begin{array}{l}\text { Tema 2: } \\
\text { Consumo de água para manter o funcionamento } \\
\text { da cidade. } \\
\text { Critério: Uma cidade terá redução no consumo } \\
\text { de água quando utilizar adequadamente a água } \\
\text { disponível. }\end{array}$} & I 10: Consumo per capita de água (m³/hab.). & Negativa (-) \\
\hline & I 11: Perdas na distribuição de água (\%). & Negativa (-) \\
\hline & I 12: Participação das economias residenciais de água (\%). & Positiva (+) \\
\hline & I 13: Extensão da rede de abastecimento de água (km). & Positiva (+) \\
\hline & I 14: Atendimento urbano de água (\%). & Positiva (+) \\
\hline & I 15: Tarifa média de água [RS/m³]. & Positiva (+) \\
\hline \multirow{4}{*}{$\begin{array}{l}\text { Tema 3: Pressão técnica urbana das populações e } \\
\text { das atividades no espaço urbano. } \\
\text { Critério: Uma cidade terá menor pressão técnica, } \\
\text { quanto menor for a pressão demográfica, industrial, } \\
\text { automotiva e das construções. }\end{array}$} & I 16: Pressão demográfica (crescimento populacional). & Negativa (-) \\
\hline & I 17: Pressão industrial (número de empresas para cada 1.000 hab.). & Negativa (-) \\
\hline & I 18: Pressão automotiva (quantidade de automóveis/hab.). & Negativa (-) \\
\hline & $\begin{array}{l}\text { I 19: Edificaç̃ões em andamento (proporção de edificaç̃oes em andamento em relação ao } \\
\text { total já existente). }\end{array}$ & Negativa (-) \\
\hline \multirow{8}{*}{$\begin{array}{l}\text { Tema 4: Distribuição espacial da pressão técnica } \\
\text { no espaço urbano. } \\
\text { Critério: Uma cidade terá melhor distribuição } \\
\text { espacial quando equalizar a distribuição da pressão } \\
\text { técnica das populações e das atividades sobre a } \\
\text { base de serviços ambientais urbanos. }\end{array}$} & I 20: Razão entre população rural e urbana. & Positiva (+) \\
\hline & I 21: Razão entre moradias na zona rural em relação à urbana. & Positiva (+) \\
\hline & I 22: Densidade demográfica (distribuição da população/km²). & Negativa (-) \\
\hline & I 23: Densidade demográfica urbana (distribuição da população/km² na área urbana). & Negativa (-) \\
\hline & I 24: Domićlios não ocupados no município (\%). & Negativa (-) \\
\hline & I 25: Déficit habitacional (população sem moradia no município). & Negativa (-) \\
\hline & I 26: Assentamentos planejados (\%). & Positiva (+) \\
\hline & I 27: Extensão das unidades de conservação (extensão da área de conservação em km²). & Positiva (+) \\
\hline
\end{tabular}

Fonte: Elaboração própria (2012). 
Quadro 1 - Temas, critérios e indicadores da dimensão racionalidade ecoenergética

(conclusão)

\section{Dimensão 1: racionalidade ecoenergética}

Tema 1 e critério

Tema 5: Produção e destino dos resíduos na cidade.

Critério: Uma cidade terá redução do volume dos resíduos quando mais adequadas forem as formas $\mathrm{e}$ a gestão de produção.
Indicadores

I 28: Quantidade de resíduos sólidos domiciliares per capita (hab./dia).

I 29: Quantidade de resíduos sólidos (entulhos) per capita (hab./dia).

I 30: Quantidade de resíduos em caixa estacionária per capita (hab./dia).

I 31: Quantidade de resíduos de podas per capita (hab./dia).

I 32: Quantidade de resíduos hospitalares per capita (hab./dia).

I 33: Quantidade de resíduos sólidos urbanos per capita (hab./dia).

I 34: Repasse de resíduos sólidos coletados para outro município.

I 35: Existência de empresas de tecnologias para reciclagem de materiais.

I 36: Existência de empresas de produção de energias alternativas.

I 37: Existência de tecnologias patenteadas para reciclagem.

Critério: Uma cidade adotará mais tecnologias ecoeficientes, quanto mais produzir tecnologias poupadoras e de reciclagem.

Tema 7: Base social de apoio por meio de projetos e de empresas que viabilizam a mudança técnica urbana.

Critério: Uma cidade melhor constituirá sua base social de apoio, quanto mais projetos e ações ambientais envolvendo a população forem criados.
I 38: Existência de projetos de educação ambiental.

I 39: Existência de projetos para conscientização ecológica da população.

I 40: Existência de projetos comunitários de reciclagem.

I 41: Existência de empresas especializadas em serviços ambientais.

I 42: Existência de empresas de reciclagem.
Relação com a sustentabilidade
Negativa (-)
Negativa $(-)$
Negativa (-)
Negativa (-)
Negativa (-)
Negativa (-)
Positiva (+)
Positiva (+)
Positiva (+)
Positiva (+)
Positiva (+)
Positiva (+)
Positiva (+)
Positiva (+)
Positiva ( + )

Fonte: Elaboração própria (2012).

A operacionalização desses indicadores possibilita gerar informações sobre os aspectos da pressão exercida pelo espaço urbano e sobre suas atividades em relação aos recursos naturais.

A dimensão 2, metabolismo urbano, complementa a análise da matriz 1, tendo como critério de análise: uma cidade terá melhor metabolismo urbano quando seus ecossistemas urbanos apresentarem capacidade adaptativa para superar as condições de vulnerabilidade diante das ameaças externas, mantendo o equilíbrio entre a utilização dos recursos e a geração de rejeitos. Os temas desta dimensão estão definidos no Quadro 2.

A mensuração desses temas e dos indicadores gera informações sobre a capacidade de a cidade reagir às mudanças em seus processos de desenvolvimento, apontando caminhos para o equilíbrio dos fluxos de recursos e dos rejeitos provocados pelas atividades humanas.

A matriz 2, a cidade como espaço de qualidade de vida, tem como critério de análise: uma cidade terá qualidade de vida quando promover o acesso às condições saudáveis de existência, de cidadania e de identidade do espaço local. As dimensões analisadas são: pureza, cidadania e patrimônio.

A dimensão 3, pureza, utiliza o seguinte critério de análise: uma cidade apresentará as condições saudáveis de existência, quanto mais conhecer as consequências das práticas e tecnologias urbanas e, assim, questionar e reduzir as implicações sanitárias dessas práticas. Os temas da dimensão pureza estão dispostos no Quadro 3.

Os temas e os indicadores de pureza geram informações sobre as condições ambientais para uma vida com qualidade, com menos contaminação das áreas urbanas e implicações sanitárias. Essas condições devem ser resguardadas pelos direitos coletivos, conforme abordados na próxima dimensão.

A dimensão 4, cidadania, tem como critério: uma cidade melhor assegurará o direito à cidadania, quanto melhor promover o diálogo, a negociação e a 
Quadro 2 - Temas, critérios e indicadores da dimensão metabolismo urbano

\section{Dimensão 2: metabolismo urbano}

\begin{tabular}{|c|c|c|}
\hline Temas e critérios & Indicadores & $\begin{array}{l}\text { Relação com a } \\
\text { sustentabilidade }\end{array}$ \\
\hline \multirow{3}{*}{$\begin{array}{l}\text { Tema 8: Equilibrio ecológico do ecossistema } \\
\text { urbano para suportar as pressõos do consumo e das } \\
\text { atividades urbanas. } \\
\text { Critério: Uma cidade terá mais equilibrio } \\
\text { ecológico, quanto mais apresentar condiçōes } \\
\text { ecológicas para suportar as pressōes do consumo e } \\
\text { das atividadaes urbanas. }\end{array}$} & I 43: Déficit ecológico (déficit de áreas de conservacção no município). & Negativo (-) \\
\hline & $\begin{array}{l}\text { I 44: Pegada ecológica do municíio (mede-se área necessária para suportar os impactos } \\
\text { causados pelas atividades humanas). }\end{array}$ & Positivo (+) \\
\hline & I 45: Arborização urbana (percentual de árvores/hab.). & Positiva (+) \\
\hline \multirow{5}{*}{$\begin{array}{l}\text { Tema 9: Existência de legislaç̃õo. } \\
\text { Critério: Uma cidade terá melhores condicões } \\
\text { legais para seu equilibrio metabólico, quanto mais } \\
\text { abrangente e adequada for a legislação. }\end{array}$} & I 46: Existência de legislação urbanística e ambiental. & Positivo (+) \\
\hline & I 47: Existência da lei de parcelamento do solo. & Positivo (t) \\
\hline & I 48: Existência da lei de zoneamento ou equivalente. & Positivo (+) \\
\hline & I 49: Existência da legislação municipal de preservaç̦̃̃o do patrimônio histórico e cultural. & Positivo (+) \\
\hline & I 50: Existência de lei municipal que institui o programa de educaçã̃o ambiental nas escolas. & Positivo (+) \\
\hline \multirow{5}{*}{$\begin{array}{l}\text { Tema 10: Existência de normas/ incentivos/fó- } \\
\text { runs que ofereçam suporte a equilibrio metabólico. } \\
\text { Critério: Uma cidade terá melhor equilibrio meta- } \\
\text { bólico, quanto mais discursões e normas existirem. }\end{array}$} & I 51: Existênncia de Código de Postura do Município. & Positivo (+) \\
\hline & I 52: Existência de normas para construção e eddificações. & Positivo (+) \\
\hline & I 53: Existência de normas para urbanizaç̃õo e regulamentação fundiária. & Positivo (+) \\
\hline & I 54: ICMS ecológico para incentivo das práticas ambientais. & Positivo (+) \\
\hline & I 55: Existência de fóruns previstos no Estatuto da Cidade. & Positivo (+) \\
\hline
\end{tabular}

Fonte: Elaboração própria (2012).

realização de pactos que resultem na institucionalização para representação da coletividade. Os temas desta dimensão estão no Quadro 4.

As informações geradas pela dimensão cidadania mostram a capacidade que a cidade tem em estabelecer pactos e espaços para negociação que favoreçam e garantam os direitos dos cidadãos em relação à qualidade de vida. Para complementar as informações referentes à qualidade de vida, na sequência, a dimensão patrimônio permite explorar aspectos que fazem parte da história da cidade e que constituem elementos relevantes para uma qualidade de vida.

A dimensão 5, patrimônio, tem o seguinte critério de análise: uma cidade melhor preservará o patrimônio local, quanto melhor conservar seus aspectos históricos, culturais e ambientais que fizeram e fazem parte de sua história ao longo de sua existência. Os temas desta dimensão estão apresentados no Quadro 5.

As informações geradas pelos indicadores de patrimônio evidenciam aspectos presentes na evolução da cidade, os quais se constituem relevantes para a qualidade de vida da população, no sentido de conservar as raízes e a história construída e de não permitir que o processo de desenvolvimento se apague. Complementando a análise da sustentabilidade urbana, a matriz 3 evidencia as questões da legitimação e da continuidade das políticas públicas como forma de dar duração à cidade.

A matriz 3, a cidade como espaço de legitimação das políticas urbanas, tem como critério de análise: uma cidade melhor reproduzirá a legitimidade das políticas urbanas no tempo, quanto mais eficientes forem as formas de promover a gestão dos recursos públicos urbanos para adequação das ofertas de serviços urbanos às demandas sociais, garantindo a distribuição equitativa dos serviços à população. As dimensões são: eficiência e equidade.

A dimensão 6, eficiência, utiliza o seguinte critério de análise: uma cidade terá melhor eficiência na gestão dos recursos públicos, quanto mais adequadas forem as formas de promoção da capacidade política e institucional de intervenção local para atender às prioridades locais. Os temas estão expostos no Quadro 6. 
Para complementar essas informações, a dimensão equidade fornece aspectos da distribuição adequada dos serviços à população.

A dimensão 7, equidade, tem como critério: uma cidade terá mais equidade na distribuição dos serviços à população, quanto melhores forem as condições habitacionais, educacionais, socioeconômicas, de segurança pública e o acesso aos serviços de transportes e de saúde. Os temas desta dimensão estão no Quadro 7.

Quadro 3 - Temas, critérios e indicadores da dimensão pureza

\begin{tabular}{|c|c|c|}
\hline \multicolumn{3}{|c|}{ Dimensão 3: pureza } \\
\hline Temas e critérios & Indicadores & $\begin{array}{l}\text { Relação com a } \\
\text { sustentabilidade }\end{array}$ \\
\hline $\begin{array}{l}\text { Tema 11: Qualidade do ar. } \\
\text { Critério: Uma cidade terá melhor qualidade do ar, } \\
\text { quanto menores forem as emissōes de substâncias } \\
\text { tóxicas e nocivas no ar. }\end{array}$ & I 56: Nível de concentraçẵo de poluentes na área urbana. & Negativa (-) \\
\hline \multirow{6}{*}{$\begin{array}{l}\text { Tema 12: Qualidade das águas em relacãão à pre- } \\
\text { sença de cloro residual, turbididez e coliformes totais. } \\
\text { Critério: Uma cidade terá melhor qualidade das } \\
\text { águas, quanto mais adequado for seu monitora- } \\
\text { mento. }\end{array}$} & I 57: Taxa de conformidade da amostra para aferição do cloro residual na água. & Positivo (+) \\
\hline & I 58: Proporção de amostras de cloro residual dentro do padrão de qualidade. & Positivo (+) \\
\hline & I 59: Taxa de conformidade da amostra para aferição de turbidez na água. & Positivo (+) \\
\hline & I 60: Proporç̃õo de amostras de turbidez dentro do padrão de qualidade. & Positivo (+) \\
\hline & 161: Taxa de conformidade da amostra para aferição de coliformes totais na água. & Positivo ( + ) \\
\hline & I 62: Proporção de amostras de coliformes totais dentro do padrão de qualidade. & Positivo (+) \\
\hline \multirow{6}{*}{$\begin{array}{l}\text { Tema 13: Implicações sanitárias nas condiçōes de } \\
\text { vida e de saúde da populaçáo. } \\
\text { Critério: Uma cidade terá menores implicacãoses } \\
\text { sanitárias, quanto menores forem as emissoess de } \\
\text { substâncias tóxicas que causam doenças e óbitios. }\end{array}$} & I 63: Quantidade de óbito por doenças infecciosas e parasitárias para cada 1.000 hab. & Negativo $(-)$ \\
\hline & $\begin{array}{l}\text { I 64: Quantidade de óbito por doenças endócrinas, nutricionais e metabólicas para cada } \\
\text { 1.000 hab. }\end{array}$ & Negativo $(-)$ \\
\hline & I 65: Quantidade de óbito por doenças do aparelho respiratório para cada 1.000 hab. & Negativo (-) \\
\hline & I 66: Quantidade de óbito por doença do aparelho digestivo para cada 1.000 hab. & Negativo (-) \\
\hline & $\begin{array}{l}\text { I 67: Quantidade de óbito por doenças da pele e do tecido subcutâneo para cada } 1.000 \\
\text { hab. }\end{array}$ & Negativo $(-)$ \\
\hline & $\begin{array}{l}\text { I 68: Quantidade de óbito por malformações congênitas, deformidades e anomalias } \\
\text { cromossômicas para cada } 1.000 \text { hab. }\end{array}$ & Negativo (-) \\
\hline \multirow{10}{*}{$\begin{array}{l}\text { Tema 14: Redução da contaminacão das áreas } \\
\text { urbanas. } \\
\text { Critério: Uma cidade terá reducuão da contaminação } \\
\text { das áreas urbanas, quanto melhores forem as } \\
\text { medidas preventivas e mitigadoras adotadas. }\end{array}$} & 1 69: Existênncia de sistema de abastecimento de água. & Positivo (+) \\
\hline & 170: Proporção de água tratada em ETA(s) em relação à água produzida. & Positivo (+) \\
\hline & I 71: Existência de sistema de esgotamento sanitário. & Positivo (+) \\
\hline & I 72: Proporção de esgoto tratado em relação ao coletado. & Positivo (+) \\
\hline & $\begin{array}{l}\text { I 73: Existência de unidades de processamento dos resíduos sólidos, tipo aterro } \\
\text { sanitário. }\end{array}$ & Positivo (+) \\
\hline & I 74: Existência de sistema de coleta seletiva de resíduos sólidos. & Positivo (+) \\
\hline & I 75: Serviços de limpeza urbana. & Positivo (+) \\
\hline & $\begin{array}{l}\text { I 76: Execucuão de coleta diferenciada de pneus velhos, lâmpadas fluorescentes, resíduos } \\
\text { de eletrônicos, pilhas e baterias. }\end{array}$ & Positivo (+) \\
\hline & I 77: Monitoramento da qualidade do ar. & Positivo (t) \\
\hline & $\begin{array}{l}\text { I 78: Proporcão de infracōoes com multas por descumprimento da legislação ambiental } \\
\text { em relação cos demais munićpios do estado. }\end{array}$ & Negativo (-) \\
\hline
\end{tabular}

Fonte: Elaboração própria (2012). 
Quadro 4 - Temas, critérios e indicadores da dimensão cidadania

\section{Dimensão 3: cidadania}

\section{Tema e critérios}

Tema 15: Participaç̃õo eleitoral. Critério: Uma cidade terá participação eleitoral, quanto maior for o comparecimento da população nas eleições e representação equitativa dos cargos por gênero.

Tema 16: Envolvimento e participaccão cívica para garantir o direito à cidadania.

Critério: Uma cidade terá participaç̦̃o cívica, quanto melhor promover açōes, projetos $\mathrm{e}$ movimentos envolvendo a população.

Tema 17: Organizaçōes representativas para assegurar os direitos da coletividade.

Critério: Uma cidade será mais bem representada em sua coletividade, quanto melhor estruturadas e abrangentes forem suas organizaçōes.

Tema 18: Conselhos Municipais visando assegurar os direitos da coletividade.

Critério: Uma cidade será mais bem representada em sua coletividade, quanto mais abrangente for a atuaç̃õo dos Conselhos Municipais.

\section{Indicadores}

I 79: Proporç̃õo de eleitores que compareceram nas úlimas eleições.

1 80: Percentual de mulheres eleitas na última eleiçõo municipal.

1 81: Existência de projetos envolvendo as organizaçōes militares e a sociedade.

I 82: Existência do Plano Diretor Participativo.

I 83: Existência de movimentos comunitários atuantes.

1 84: Percentual de projetos encaminhados ao órgão legislativo por iniciativa popular.

1 85: Percentual de bairros engajados em projetos ambientais.

1 86: Existência da comissão de urbanização e legalização.

1 87: Existência de órgão ambiental (fiscalização e controle).

1 88: Existência de órgão ambiental (coordenadoria).

189: Existência de ONGS ambientalistas.

1 90: Existência de centrais de denúncia dos impactos ambientais das atividades econômicas.

191: Existência de cooperativas por toneladas de resíduos.

1 92: Existência de cooperativas de produtores e de vendedores de produtos orgânicos por 1.000 hab.

1 93: Existência do Conselho Municipal de Transporte.

I 94: Existência do Conselho Municipal de Política Urbana, Desenvolvimento Urbano, da Cidade ou similar.

195: Existência do Conselho Municipal de Habitacãõo.

1 96: Existência do Conselho Municipal de Meio Ambiente.

1 97: Existência do Conselho Municipal de Segurança Pública.

I 98: Existência do Conselho Municipal do Patrimônio Cultural.
Relação com a sustentabilidade

Positiva ( + )

Positiva (+)

Positiva (+)

Positiva (+)

Positiva (+)

Positiva (+)

Positiva (+)

Positiva (+)

Positiva (+)

Positiva (+)

Positiva $(+)$

Positiva $(+)$

Positiva $(+)$

Positiva (+)

Positiva (+)

Positiva (+)

Positiva (+)

Positiva (t)

Positiva (+)

Positiva $(+)$

Fonte: Elaboraçãoo própria (2012).

Quadro 5 - Temas, critérios e indicadores da dimensão patrimônio

\section{Dimensão 3: patrimônio}

\section{Temas e critérios}

Tema 19: Patrimônio natural.

Critério: Uma cidade preservará seu patrimônio natural e ambiental, quanto mais forem conservados os aspectos naturais do espaço urbano.

Tema 20: Patrimônio histórico e cultural.

Critério: Uma cidade preservará seu patrimônio histórico e cultural, quanto mais forem valorizados os aspectos que fazem parte de sua identidade histórica e cultural.

Tema 21: Integridade do patrimônio.

Critério: Uma cidade preservará seu patrimônio quando mantiver a integridade de seu patrimônio.

\section{Indicadores}

I 99: Percentual de árvores centenárias tombadas.

I 100: Reservas naturais preservadas (razão entre as áreas de reservas naturais preservadas e as demais áreas).

I 101: Existência de parques e de jardins catalogados como históricos.

I 102: Tombamento do patrimônio histórico arquitetônico do município.

I 103: Existência de museu histórico e cultural.

I 104: Integridade do patrimônio histórico e cultural.

I 105: Existência de órgãos de fiscalização do patrimônio histórico e artístico no município.

I 106: Existência de projetos para valorização do patrimônio.

I 107: Recuperação da arquitetura histórica cidade.
Relação com a sustentabilidade

Positiva (+)

Positiva (+)

Positiva (+)

Positiva ( + )

Positiva (t)

Positiva (+)

Positiva (+)

Positiva (+)

Positiva (t)

Fonte: Elaboraç̃̃o própria (2012). 
Quadro 6 - Temas, critérios e indicadores da dimensão eficiência

\begin{tabular}{|c|c|c|}
\hline \multicolumn{3}{|c|}{ Dimensão 6: eficiência } \\
\hline Temas e critérios & Indicadores & $\begin{array}{l}\text { Relação com a } \\
\text { sustentabilidade }\end{array}$ \\
\hline $\begin{array}{l}\text { Tema 22: Desenvolvimento municipal. } \\
\text { Critério: Uma cidade terá melhor desenvolvimento municipal, } \\
\text { quanto melhor for seu desempenho em educação, saúde e } \\
\text { emprego/renda. }\end{array}$ & I 108: Índice Firian de Desenvolvimento Municipal (IFDM). & Positiva (+) \\
\hline \multirow{10}{*}{$\begin{array}{l}\text { Tema 23: Despesas municipais. } \\
\text { Critério: Uma cidade terá melhor desenviolvimento urbano, quanto } \\
\text { melhor distribuir os recursos públicos para atender às prioridades } \\
\text { urbanas locais. }\end{array}$} & I 109: Despesas com planejamento e orçamento. & Positiva (+) \\
\hline & I 110: Despesas com segurança pública. & Positiva (+) \\
\hline & I 111 : Despesas com urbanismo. & Positiva ( + ) \\
\hline & I 112: Despesas com infraestrutura urbana. & Positiva (+) \\
\hline & I 113: Despesas com habitação urbana. & Positiva (+) \\
\hline & I 114: Despesas com saneamento básico urbano. & Positiva ( + ) \\
\hline & I 115: Despesas com gestão ambiental. & Positiva (+) \\
\hline & I 1 16: Despesas com patrimônio cultural e difusão da cultura. & Positiva (+) \\
\hline & I 117: Despesas com direito à cidadania. & Positiva (+) \\
\hline & I 1 18: Despesas com melhoria e ampliação do sistema de transporte. & Positiva (+) \\
\hline \multirow{3}{*}{$\begin{array}{l}\text { Tema 24: Receitas municipais na gestão municipal. } \\
\text { Critério: Uma cidade terá melhor desenviolvimento urbano, quanto } \\
\text { melhor gerir os recursos públicos para manutenção do espaço } \\
\text { público urbano. }\end{array}$} & I 1 19: Quantidade de receitas municipais per capita a0 ano. & Positiva (+) \\
\hline & I 120: Razão entre receitas próprias e transferências. & Positiva (+) \\
\hline & $\begin{array}{l}\text { I 121: Existência de instrumentos econômicos no gerenciamento dos } \\
\text { recursos naturais. }\end{array}$ & Positiva (+) \\
\hline \multirow{5}{*}{$\begin{array}{l}\text { Tema 25: Capacidade político-institucional de intervencão local. } \\
\text { Critério: Uma cidade terá mais capacidade política e institucional, } \\
\text { quanto mais adequadas forem as formas de articulação local. }\end{array}$} & $\begin{array}{l}\text { I 122: Percentual de dependência do município em relação às transferên- } \\
\text { cias governamentais. }\end{array}$ & Negativa $(-)$ \\
\hline & $\begin{array}{l}\text { I 123: Aprovacã̃o de projetos urbanos do Plano de Aceleração do } \\
\text { Crescimento (PÁC). }\end{array}$ & Positiva (+) \\
\hline & I 124: Existência do Fundo Municipal de Habitação. & Positiva (+) \\
\hline & I 125: Existência da Secretaria Municipal de Planejamento Urbano. & Positiva (+) \\
\hline & I 126: Existência da Superintendência de Trânsito e Transportes Públicos. & Positiva (+) \\
\hline
\end{tabular}

Fonte: Elaboraçãao própria (2012).

Esses indicadores complementam a análise da sustentabilidade, mediante informações sobre o acesso da população aos serviços públicos.

Diante do exposto, pode-se afirmar que o modelo apresentado é composto por um conjunto de indicadores que produz uma significativa quantidade de informações sobre a problemática urbana, apontando caminhos para a elaboração, implementação e ajuste das políticas públicas urbanas, no sentido de buscar uma adequação para atender às prioridades da cidade e, assim, melhorar o desempenho da sustentabilidade urbana. Vale salientar que a escolha final desses indicadores deve considerar as características da localidade como forma de adequá-los à problemática urbana local.

\section{Considerações finais}

Para análise da sustentabilidade, é necessário entender que o espaço urbano surge como uma extensão do espaço natural, de tal modo que as limitações da capacidade de resiliência da própria natureza imponham as barreiras da sustentabilidade urbana, o que requer uma percepção ampla do processo de análise da sustentabilidade urbana para captar as 
Quadro 7 - Temas, critérios e indicadores da dimensão equidade

(continua)

\begin{tabular}{|c|c|c|}
\hline \multicolumn{3}{|c|}{ Dimensão 6: equidade } \\
\hline Temas e critérios & Indicadores & $\begin{array}{l}\text { Relação com a } \\
\text { sustentabilidade }\end{array}$ \\
\hline \multirow{6}{*}{$\begin{array}{l}\text { Tema 26: Condiçōes habitacionais. } \\
\text { Critério: Uma cidade terá melho- } \\
\text { res condicōes habitacionais, quanto } \\
\text { mais adequadas forem as políiticas } \\
\text { urbanas para democratizar o acesso } \\
\text { da população a esses serviciçs. }\end{array}$} & I 127: Percentual de domicilios no municíio com densidade adequada. & Positivo (+) \\
\hline & I 128: Percentual de domićlios urbanos adequados, considerando o tipo de saneamento. & Positivo (+) \\
\hline & I 129: Proporção de crianças ( 0 a 5 anos) residentes em domićlios com saneamento inadequado. & Negativo $(-)$ \\
\hline & I 130: Média de moradores em domićlios particulares ocupados. & Negativo (-) \\
\hline & I 131: Percentual da população residente em domićlios ocupados em aglomerados subnormais. & Negativo $(-)$ \\
\hline & I 132: Percentual de domićlios ocupados nos aglomerados subnormais. & Negativo (-) \\
\hline \multirow{8}{*}{$\begin{array}{l}\text { Tema 27: Condiçōes socioeco- } \\
\text { nômicas. } \\
\text { Critério: Uma cidade terá melho- } \\
\text { res condiçōes sociais e econôomicas, } \\
\text { quanto mais equitativas forem as } \\
\text { políticas sociais e econômicas. }\end{array}$} & I 133: Produto Interno Bruto (PIB) per capita. & Positivo (+) \\
\hline & I 134: Quantidade média de pessoal ocupado (trabaha) por domicilio. & Positivo (+) \\
\hline & $\begin{array}{l}\text { I 135: Proporç̃o de pessoas (urbanas) com rendimento mensal domicliar per capita de até l/4 salário } \\
\text { mínimo (RS). }\end{array}$ & Negativo (-) \\
\hline & I 136: Rendimento mensal domiciliar per capita nominal (valor médio urbano). & Positivo (+) \\
\hline & I 137: Percentual de populaç̃̃o que recebe auxilio do governo federal. & Negativo (-) \\
\hline & $\begin{array}{l}\text { I 138: Razão entre a populacão considerada inativa ( } 0 \text { a } 14 \text { anos e } 60 \text { anos ou mais de idade) e a } \\
\text { população potencialmente ativa ( } 15 \text { a } 59 \text { anos de idade). }\end{array}$ & Negativo (-) \\
\hline & I 139: Percentual da população urbana em extrema pobreza. & Negativo (-) \\
\hline & I 140: Expressa o grau de concentração na distribuicçõo dos rendimentos. & Negativo (-) \\
\hline \multirow{7}{*}{$\begin{array}{l}\text { Tema 28: Condicốes educacionais. } \\
\text { Critério: Uma cidade terá melho- } \\
\text { res condiçôes educacionais quando } \\
\text { mais equitativo for o acesso da } \\
\text { população cos serviços públicos. }\end{array}$} & I 141: Proporção da população alfabetizada para o grupo com idade acima de 6 anos. & Positivo (+) \\
\hline & $\begin{array}{l}\text { I 142: Proporç̃̃o de pessoas consideradas potencialmente ativas ( } 15 \text { a } 59 \text { anos de idade) que não sabem } \\
\text { ler e escrever. }\end{array}$ & Negativo (-) \\
\hline & I 143: Taxa de não resposta (TNR) nos ensinos fundamental e médio urbano. & Positivo $(+)$ \\
\hline & I 144: Taxa de abandono nos ensinos fundamental e médio urbano. & Negativo $(-)$ \\
\hline & I 145: Taxa média de reprovação nos ensinos fundamental e médio urbano. & Negativo (-) \\
\hline & I 146: Taxa média de aprovacã̃o no ensino fundamental e médio urbano. & Positivo $(+)$ \\
\hline & I 147: Taxa de distorção idade-série nos ensinos fundamental e médio urbano. & Negativo (-) \\
\hline \multirow{8}{*}{$\begin{array}{l}\text { Tema 29: Acesso aos servicicos } \\
\text { básicos. } \\
\text { Critério: Uma cidade terá melhor } \\
\text { acesso aos servicos básicos quando } \\
\text { mais equitativo for a distribuicịão à } \\
\text { populaçãóo. }\end{array}$} & I 148: Proporç̃̃o de domićlios com abastecimento de água via rede geral. & Positivo $(+)$ \\
\hline & I 149: Proporç̣̃a de domićlios com banheiro e esgotamento sanitário via rede geral. & Positivo (+) \\
\hline & I 150: Proporção de domićlios com destino do lixo coletado. & Positivo (+) \\
\hline & I 151: Percentual de domićlios com acesso à rede elétrica. & Positivo (+) \\
\hline & I 152: População urbana do município atendida com serviço de coleta de resíduos. & Positivo (+) \\
\hline & $\begin{array}{l}\text { I 153: Percentual da populacacão atendida com frequência de duas ou três vezes por semana pelo serviciç } \\
\text { de coleta de resíduos. }\end{array}$ & Positivo (+) \\
\hline & I 154: Acesso à telefonia. & Positivo ( + ) \\
\hline & I 155: Acesso à internet. & Positivo (+) \\
\hline \multirow{6}{*}{$\begin{array}{l}\text { Tema 30: Acesso a serviço de } \\
\text { transporte. } \\
\text { Critério: Uma cidade terá melhor } \\
\text { acesso aos servicos de transporte } \\
\text { quando mais equitativo for sua } \\
\text { distribuição à população. }\end{array}$} & I 156: Oferta de transporte público. & Positivo (+) \\
\hline & I 157: Sistema integrado de transporte coletivo. & Positivo ( + ) \\
\hline & I 158: Quantidade média de ônibus por linhas. & Positivo ( + ) \\
\hline & I 159: Quantidade de ônibus para cada 1.000 hab. & Positivo ( + ) \\
\hline & I 160: Área do município atendida com o sistema de transporte coletivo (\%). & Positivo (+) \\
\hline & I 161: Percentual da frota de ônibus aprovados quanto aos limites de emissão de fumaça (CONAMA). & Positivo (+) \\
\hline
\end{tabular}

Fonte: Elaboração própria (2012).

urbe. Revista Brasileira de Gestão Urbana (Brazilian Journal of Urban Management), 2015 set./dez., 7 (3), 397-410 
Quadro 7 - Temas, critérios e indicadores da dimensão equidade

(conclusão)

\section{Dimensão 6: equidade}

\begin{tabular}{|c|c|c|}
\hline \multicolumn{3}{|c|}{ Dimensão 6: equidade } \\
\hline Temas e critérios & Indicadores & $\begin{array}{l}\text { Relação com a } \\
\text { sustentabilidade }\end{array}$ \\
\hline \multirow{6}{*}{$\begin{array}{l}\text { Tema 31: Condiçōes de segurança } \\
\text { pública. } \\
\text { Critério: Uma cidade terá melhor } \\
\text { acesso cos servicos de segurança } \\
\text { pública, quanto mais equitativa e } \\
\text { democrática for a sua distribuiç̃ão à } \\
\text { população. }\end{array}$} & I 162: Número de bombeiros para cada 1.000 hab. & Positivo $(+)$ \\
\hline & I 163: Efetivo da polícia civil para cada 1.000 hab. & Positivo ( + ) \\
\hline & I 164: Efetivo da polícia militar (PM) para cada 1.000 hab. & Positivo (+) \\
\hline & I 165: Taxa de vítimas de acidentes de trânsito para cada 100 mil hab. & Negativo (-) \\
\hline & I 166: Taxa de homićdios para cada 100 mil hab. & Negativo $(-)$ \\
\hline & I 167: Taxa de sucídilios para cada 100 mil hab. & Negativo (-) \\
\hline \multirow{5}{*}{$\begin{array}{l}\text { Tema 32: Acesso a serviço de } \\
\text { saúde. } \\
\text { Critério: Uma cidade terá melhor } \\
\text { acesso cos servicos de saúde, } \\
\text { quanto mais equitativa for a sua } \\
\text { distribuicịão à população. }\end{array}$} & I 168: Proporç̦ão da população atendida com o Programa de Saúde da Família (PSF). & Positivo (+) \\
\hline & I 169: Número de médicos por 100 mil hab. & Positivo (+) \\
\hline & I 170: Quantidade média de médicos por estabelecimento de saúde. & Positivo (+) \\
\hline & I 171: Número de leitos hospitalares por 100 mil hab. & Positivo (+) \\
\hline & I 172: Número de habitantes por estabelecimento de saúde. & Negativo (-) \\
\hline
\end{tabular}

Fonte: Elaboração própria (2012).

sutilezas dos processos naturais e urbanos, a partir de formas sistêmicas de análises.

0 artigo propõe um modelo para análise da sustentabilidade que é abrangente à problemática das cidades brasileiras, uma vez que utiliza como suporte teórico conceitual as três principais vertentes da sustentabilidade urbana, representados pelas matrizes (a cidade em seus aspectos técnico-materiais, a cidade como espaço de qualidade de vida e a cidade como espaço de legitimação das políticas públicas). 0 modelo conceitual foi utilizado como base para a definição dos critérios de sustentabilidade, que serviram de pilares para a seleção dos indicadores adequados à análise da sustentabilidade urbana, possibilitando reduzir a subjetividade da sustentabilidade e os diversos desafios decorrentes, para resultar em uma classificação coerente do nível de sustentabilidade das cidades ao longo dos anos.

No entanto, não foi possível encontrar todos os indicadores para compor o modelo nos sistemas de indicadores já existentes, sendo necessário propor e calcular novos indicadores que fossem adequados aos propósitos da investigação. Assim, o modelo permite ampliar e diversificar os indicadores utilizados nos sistemas de indicadores e de análises da sustentabilidade urbana, contribuindo para melhor retratar e absorver a problemática urbana atual.

Conclui-se que o modelo permite analisar a sustentabilidade de cidades, além de possibilitar construir padrões de comparação ao longo dos anos que favoreçam o monitoramento da sustentabilidade e a geração de informações relevantes para o processo de elaboração e de implementação de políticas públicas, as quais permitirão incorporar um processo de desenvolvimento embasado em princípios sustentáveis para dotar a cidade de condições favoráveis ao processo de desenvolvimento sustentável. Assim, a pesquisa contribui para os estudos da sustentabilidade urbana, uma vez que consegue trabalhar em uma vertente teórica a partir da leitura das matrizes da sustentabilidade urbana, buscando uma relação com a realidade prática por meio dos indicadores urbanos, de modo a permitir uma orientação para o processo de desenvolvimento urbano das cidades.

Sugere-se que o modelo seja aplicado em diferentes cidades brasileiras para confirmar sua aplicabilidade em diferentes realidades. Além disso, a partir dessa listagem inicial de indicadores, deve-se incorporar a participação local para seleção e para ponderação dos indicadores urbanos que melhor retratem as vulnerabilidades e as prioridades locais. Recomenda-se também a incorporação de técnicas estatísticas para seleção dos indicadores mais adequados para compor cada tema e para definir a relação positiva e negativa para a sustentabilidade. A partir dessas preocupações, o modelo permite analisar a sustentabilidade e os reflexos das decisões políticas, favorecendo a adoção de políticas urbanas de acordo com os pontos de 
insustentabilidade do espaço urbano, de tal modo que o monitoramento permita a continuidade das políticas e a incorporação de um processo de planejamento para a construção de cidades sustentáveis.

\section{Referências}

Acselrad, H. (1999). Discursos da sustentabilidade urbana. Revista de Estudos Urbanos e Regionais - ANPUR, 1(1), 79-90.

Acselrad, H. (2009). A duração das cidades: sustentabilidade e risco nas políticas urbanas (2. ed.). Rio de Janeiro: Lamparina.

Braga, T. M. (2006). Sustentabilidade e condições de vida em áreas urbanas: medidas e determinantes em regiões metropolitanas brasileiras. Revista Eure, 32(96), 47-71.

Bremer, U. F. (2004). Por nossas cidades sustentáveis. In Anais do V CNP/LXI SOEAA. Brasília: CONFEA.

Canepa, C. (2007). Cidades sustentáveis: o município como lócus da sustentabilidade. São Paulo: RCS.

Castells, M. (2000). A questão urbana. São Paulo: Paze Terra.

Left, H. (2000). Saber ambiental (2. ed.). Petrópolis: Vozes.

Martins, M. F., \& Cândido, G. A. (2013). Análise da sustentabilidade urbana no contexto das cidades: proposição de critérios e indicadores. In Anais do XXXVII EnANPAD. Rio de Janeiro: ANPAD.
Mendonça, F. (2001). Abordagem interdisciplinar da problemática ambiental urbano-metropolitana: esboço metodológico da experiência do doutorado em MA\&D* da UFPR sobre a RMC - Região Metropolitana de Curitiba. Desenvolvimento e Meio Ambiente, 3, 79-95.

Metzger, P. (1994). Contribution à une problématique de l'environnement urbain. Cahiers des Sciences Humaines, $30(4), 596-598$.

Moreno, J. (2002). O futuro das cidades. São Paulo: Senac São Paulo.

Mumford, L. (2008). A cidade na história: suas origens, transformações e perspectivas (5. ed.). São Paulo: Martins Fontes.

Rattner, H. (2009). Prefácio. In H. Acselrad. A duração das cidades: sustentabilidade e risco nas políticas urbanas (2. ed.). Rio de Janeiro: Lamparina.

Rogers, R. (2008). Cidades para um pequeno planeta. Barcelona: Editorial Gustavo Gili.

Silva, L. S., \& Travassos, L. (2008). Problemas ambientais urbanos: desafios para a elaboração de políticas públicas integradas. Cadernos Metrópole, 19, 27-47.

Recebido: Fev. 2, 2015

Aprovado: Abr. 7, 2015 